\title{
An essay on the psychological effects of quarantine in SARS-CoV-2 pandemic
}

\author{
Un ensayo sobre los efectos psicológicos de la cuarentena en la pandemia de SARS-CoV-2
}

\section{Dear Editor:}

Several surveys have highlighted the impacts on mental health due to quarantine (1). It is noteworthy the spaces involved in the quarantine, as it involves separating and restricting the movement of people who have been potentially exposed to a contagious disease, in order to check whether they are sick, thereby reducing the risk of infecting other people. Initially used to control the disease in China, quarantine has been used recently in the 2019 SARS-CoV-2, coronavirus disease outbreak (COVID-19) in Europe- in which Italy has become the disease epicenter, with the entire country quarantined. This outbreak is causing entire cities to be effectively isolated en masse (2).

The symptoms of post-traumatic stress, resulting from the uncertainties caused by the coronavirus disease (COVID-19), associated with the behaviors related to escape and anger, make up the behaviors as to the quarantine duration. Length of stay is another indicator for the main events involved in posttraumatic situations. It is important to observe how the quarantine has drastically reduced people interactions. It initially causes a visual shock and emptiness, and loneliness scenarios. Later, there is high prevalence of suffering and psychological disturbance symptoms.

Most studies highlighted the presence of psychological symptoms that emerged from psychological pain and suffering. Such disorders were caused by psychologically vulnerable individuals and their trauma environments, depressive symptoms interconnected with uncertainties and death prospects, movement of stressful and borderline situations involved with family relationships, uncontrolled mood due to loneliness and uncertainties generated by the disease, circumscribed irritability in a situation of emotional and visual shock, oscillating insomnia, persistent anger, and affective and emotional exhaustions (3).

The findings that need to be reflected by the psychiatry community are the intercurrent symptoms of insertion in alcohol dependence and behavioral movement, which would lead to a greater chance of abuse by health professionals (4). Stigmatization, behaviors of avoidance after quarantine, and living in a frustration, guilt and helplessness environment, consequently, incite isolation and loneliness in health professionals (5). And yet, while anxiety among people subjected to quarantine is troubling, perhaps the most pernicious effect is on how those outside the cordon notice those on the other side. Unless active steps are taken to avoid stigmatizing those who have been under quarantine, the official imposition of a cordon may aggravate such effects. Isolation imposed by vigilantes can follow, or even run ahead of, official quarantine (1).

Therefore, if the quarantine experience is negative, results suggest long-term consequences that will not

\footnotetext{
School of Medicine, Federal University of Cariri (UFCA). Barbalha, Ceará, Brazil.

Department of Internal Medicine, Santa casa de Misericórdia de Fortaleza. Fortaleza, Ceará, Brazil.

Regional University of Cariri - URCA. Crato, Ceará, Brazil.

Suicidology Research Group, Universidade Federal do Ceará (UFC). Fortaleza, Ceará,, Brazil.

Titular professor of Mental Health and Psychology

Associated Physician

Associate Professor of Public Health

Associate professor of Psychology.
} 
only affect the quarantined people, but also the health system that administered the quarantine and the politicians and public health officials who determined it.

Modesto Leite Rolim Neto ${ }^{1, a}$, Jucier Gonçalves Júnior $^{2, b}$, Woneska Rodrigues Pinheiro ${ }^{3, c}$, Nádia Nara Rolim Lima ${ }^{4, \mathrm{~d}}$, Marcial Moreno Moreira ${ }^{1, \mathrm{a}, \mathrm{d}}$, Claúdio Gleideston Lima da Silva ${ }^{5, a}$

\section{Correspondence:}

Jucier Gonçalves Júnior,

Santa Casa de Misericórdia. Fortaleza, CE, Brazil.

Email: Juciergjunior@hotmail.com

\section{REFERENCES}

1. Rubin GJ, Wessely S. The psychological effects of quarantining a city. BMJ. 2020; 368:m313. DOI: 10.1136/bmj.m313
2. Webster R, Smith L, et al. The psychological impact of quarantine and how to reduce it: rapid review of the evidence. Lancet. 2020; 395:912-920. DOI: 10.1016/S0140-6736 (20) 30460-8.

3. Lee S, Chan LY, Chau AM, Kwok KP, Kleinman A. The experience of SARS-related stigma at Amoy Gardens. Soc Sci Med. 2005; 61(9): 2038-2046. DOI: 10.1016/j.socscimed.2005.04.010.

4. Wu P, Liu X, Fang Y, et al. Alcohol abuse/dependence symptoms among hospital employees exposed to a SARS outbreak. Alcohol and Alcoholism. 2008; 43(6):706-712. DOI: 10.1093/alcalc/agn073.

5. Jeong H, Yim HW, Song YJ, et al. Mental health status of people isolated due to Middle East respiratory syndrome. Epidemiol Health. 2016; 38: e2016048. DOI: 10.4178/epih.e2016048

Recibido: 21/01/2020 